\title{
BMJ Open Using the General Social Survey - National Death Index cohort to study the relationship between neighbourhood fear and mortality in the USA
}

\author{
Erin Grinshteyn (D) , ${ }^{1}$ Peter Muennig, ${ }^{2}$ Roman Pabayo ${ }^{3}$
}

To cite: Grinshteyn E, Muennig P, Pabayo R. Using the General Social Survey National Death Index cohort to study the relationship between neighbourhood fear and mortality in the USA. BMJ Open 2019;9:e030330. doi:10.1136/ bmjopen-2019-030330

- Prepublication history for this paper is available online. To view these files, please visit the journal online (http://dx.doi org/10.1136bmjopen-2019030330).

Received 11 March 2019 Revised 03 September 2019 Accepted 05 September 2019

Check for updates

(C) Author(s) (or their employer(s)) 2019. Re-use permitted under CC BY-NC. No commercial re-use. See rights and permissions. Published by BMJ.

${ }^{1}$ Health Professions Department, University of San Francisco, San Francisco, California, USA ${ }^{2}$ Mailman School of Public Health, Columbia University, New York, New York, USA ${ }^{3}$ Canada Research Chair Tier II in Social and Health Inequities Throughout the Lifespan, School of Public Health, University of Alberta, Edmonton Clinic Health Academy, Edmonton, Alberta, Canada

Correspondence to

Dr Erin Grinshteyn;

egrinshteyn@usfca.edu

\section{ABSTRACT}

Objectives Fear of crime is associated with adverse mental health outcomes and reduced social interaction independent of crime. Because mental health and social interactions are associated with poor physical health, fear of crime may also be associated with death. The main objective is to determine whether neighbourhood fear is associated with time to death.

Setting and participants Data from the 1978-2008 General Social Survey were linked to mortality data using the National Death Index (GSS-NDI) $(n=20297)$.

Methods GSS-NDI data were analysed to assess the relationship between fear of crime at baseline and time to death among adults after removing violent deaths. Fear was measured by asking respondents if they were afraid to walk alone at night within a mile of their home. Crude and adjusted HRs were calculated using survival analysis to calculate time to death. Analyses were stratified by sex. Results Among those who responded that they were fearful of walking in their neighbourhood at night, there was a $6 \%$ increased risk of death during follow-up in the adjusted model though this was not significant $(H R=1.06$, $95 \% \mathrm{Cl} 0.99$ to 1.13). In the fully adjusted models examining risk of mortality stratified by sex, findings were significant among men but not women. Among men, in the adjusted model, there was an $8 \%$ increased risk of death during follow-up among those who experienced fear at baseline in comparison with those who did not experience fear ( $\mathrm{HR}=1.08,95 \% \mathrm{Cl} 1.02$ to 1.14).

Conclusions Research has recently begun examining fear as a public health issue. With an identified relationship with mortality among men, this is a potential public health problem that must be examined more fully.

\section{INTRODUCTION}

Fear of crime has been defined as an emotional reaction that is exemplified by a sense of danger and worry due to the perception of impending physical harm. ${ }^{12}$ This perceived danger or threat can cause physiological responses such as the 'fight or flight' response, which can lead to adverse health outcomes when experienced chronically. ${ }^{34}$
Strengths and limitations of this study

- To our knowledge, this is the first study that has assessed the relationship between neighbourhood fear and mortality.

- This study shows an association between neighbourhood fear and time to death and demonstrates existing effect modification in this relationship based on gender, all of which was previously unknown.

- The potential relationship between time-varying covariates and time to death could not be described as participants were only assessed at baseline.

- Thus, non-differential misclassification of the exposure could be a concern, which would bias results towards the null.

Consequences include the deleterious effects of these biological stress responses, which include short term (eg, sweating, shortness of breath, heart rate quickening and trembling) and long term (eg, ulcers and high blood pressure) outcomes. ${ }^{5-8}$ Ross and Mirowsky ${ }^{3}$ provide an extensive review of the biological theory discussing how fear can lead to health consequences, which includes the weakening of the body's regulatory systems, making one more susceptible to illness as well as speed up the deterioration of physiological structures. ${ }^{3}$

As a result of these physiological stress responses and subsequent biological deterioration of the body's systems, fear of crime has been associated with a number of health conditions observed in populations worldwide. Increased fear was associated with reduced physical functioning (as measured by likelihood of exercising) among adults aged $35-55$ years in London. ${ }^{9}$ Other studies found that fear of crime was associated with less walking for transport and recreation among adults in Australia. ${ }^{10}{ }^{11}$ With reductions in walking and reduced physical 
function, it is unsurprising that worse perceived neighbourhood safety has also been associated with increased body mass index in the USA. ${ }^{12}$ Fear of crime has also been associated with reduced physical well-being (as measured by the SF-12) in New Zealand ${ }^{13}$ and self-reported poor health among men in Sweden ${ }^{14}$ and among adults in the UK. ${ }^{15}$ A longitudinal study in the USA found that lower perceived neighbourhood safety was associated with more chronic conditions compared with those who perceived more neighbourhood safety. ${ }^{16}$ Another longitudinal study in the USA found that those who perceived their neighbourhood safety as moderately safe or unsafe had an increased risk of functional decline (as defined as new difficulty or dependence in activities of daily living, new mobility difficulty and/or death) compared with those who rated their perceived neighbourhood safety as very safe. ${ }^{17}$ Behavioural outcomes are also affected by safety. Perception of living in an unsafe neighbourhood among a sample in California was associated with delays in filling a prescription among participants with type 2 diabetes. ${ }^{18}$

Fear of crime also has been associated with social processes that have resulting implications for both physical health and mental health outcomes. Fear of crime can lead residents to withdraw from their neighbourhoods to avoid the perceived risk. ${ }^{19}{ }^{20}$ Adults in London who reported more fear also reported seeing friends less, participation in fewer social activities and limited physical activities. ${ }^{9}$ While this withdrawal could contribute to the physical declines previously mentioned (eg, reductions in walking), this withdrawal could also lead to greater social isolation, which in turn has mental health consequences including depression. ${ }^{21}$

Thus, fear of crime has also been associated with worse mental health. Fear was associated with depression among adults aged $35-55$ years in London, ${ }^{9}$ adverse mental health outcomes (as measured by the SF-12) in in New Zealand ${ }^{13}$ and psychological distress among adults in Australia. ${ }^{22}$ However, the latter study also found evidence that there is reverse causality between fear and mental health outcomes. That is, worsening psychological distress itself can lead to increased self-rated fear, possibly because mental distress heightens all negative emotions, including fear.

Reverse causality is a concern common to most published investigations of fear and health, necessitating sophisticated causal methodology. For instance, a recent study that assessed the relationship between fear of crime and depression found that fear was associated with increased depression among adolescents. This study tried to address reverse causality by using instrumental variables (IVs) ${ }^{23}$ In the absence of randomisation, IV methods can be used to assess endogeneity by showing that the exposure rather than something unobservable is causing the outcome or that the outcome is causing the exposure (ie, reverse causality). Using IV methods, this paper found no evidence that the relationship between fear and depression suffered from endogeneity. Another approach to addressing the potential for reverse causality that exists in the relationship between fear and a number of outcomes is to explore a more concrete and plausible outcome, such as mortality, as there is a lower likelihood of reverse causality in the relationship between mortality and fear.

It is important to acknowledge observed gender differences in perceptions of fear. For example, researchers observed that women have worse perceptions of neighbourhood safety than men. ${ }^{24}{ }^{25} \mathrm{~A}$ recent paper showed that greater fear of crime among women is specifically related to perceived risk within neighbourhoods. ${ }^{26}$ In fact, a recent meta analysis found that gender had the largest effect on fear of crime than any other individual-level or area-level predictor (including previous experience with victimisation). ${ }^{27}$ However, some research has questioned this dynamic and the validity of measurements of fear among men. One study found that self-reported fear levels were inversely associated with a measure that assesses likelihood of reporting socially desirable answers. ${ }^{28}$ Thus, while men are reporting lower levels of fear, these reports may be influenced by social conditioning on expectations that men exhibit masculinity.

While much of the literature has shown that fear has been associated with adverse physical and mental health outcomes, reduced social interaction and reductions in neighbourhood social control, fear has not been examined as a risk factor for mortality. In 2016, life expectancy dropped for the second year in a row in the USA (78.6 years down from 78.7 years in 2015), ${ }^{29}$ which already lags behind other high-income countries in terms of life expectancy. Understanding risk factors for mortality is important in order to prevent these risk factors and improve life expectancy in the USA. We hypothesise that fear may be associated with risk for death. Our objectives in this paper are to (1): to begin to describe the influence of area effects such as fear of neighbourhood crime on mortality in an adult population (2) to differentiate the effect of fear within male and female populations given the extensive focus on the differences between men and women in terms of feeling fear and the resulting outcomes and (3) to propose public health approaches to address neighbourhood fear among adults. We hypothesise that fear is associated with increased risk of death overall after adjusting for potential confounders and that the increase in risk of death among women is larger than the increase in risk among men.

\section{METHODS}

\section{Study sample and design}

Data for this investigation come from the General Social Survey (GSS), a representative sample of noninstitutionalised US adults aged 18 years and older, linked to the US National Death Index (NDI). The history and philosophy of the GSS has been described elsewhere. ${ }^{30}$ Briefly, the GSS is an annual study of opinions and attitudes among the US public collected by the National Opinion Research Center at the University of Chicago. ${ }^{31}$ 
Interviews were conducted in person and involve a core set of questions asked every year. Different people were included in each year of the survey, so the survey is not a panel design. Each time new respondents were enrolled, they were asked the baseline questions. We linked 32830 respondents who were enrolled in the GSS between 1976 until 2008 to the US NDI. Violent deaths were removed from the sample because it is hypothesised that fear contributes to mortality unrelated to violence through the psychosocial and behavioural pathways previously discussed. Since the question measuring fear was not included in every year, the final analytic sample $(\mathrm{n}=20297)$ represents those who answered this question after removing violent deaths.

\section{Patient and public involvement}

We did not involve patients or the public in the design of this study. Secondary data were utilised for this project.

\section{Variables}

The outcome variable in this study was vital status. Vital status of the respondents was ascertained through 31 December 2008 using the NDI data. Of those who have died, $99.84 \%$ of the records were linked to an underlying cause of death. ${ }^{31}$ The exposure of interest was perceived neighbourhood safety, which was asked of each GSS participant only at baseline when they were enrolled in the study. They were asked about their perceived neighbourhood safety using the following question, 'Is there any area right around here-that is, within a mile, where you would be afraid to walk alone at night?'. Response categories were yes and no. We included a host of covariates to control for known confounders including age in years, gender (male/female), race/ethnicity (white, black and other), household income in dollars, divisions (using Census Divisions), religious affiliation (Protestant, Catholic, Jewish, other religion, Eastern religion and no religion) and setting (rural, urban and suburban). A cohort variable (before 1990s and after 1990s) was also included as a covariate. The beginning of the 1990s was chosen as the cut-point for determining cohorts as it corresponds roughly to the midpoint of the study and has been established by previous literature. ${ }^{32}$

\section{Statistical analysis}

Time to death was calculated using Cox proportional hazard regressions using a step-up approach. First, the crude relationship between fear and time to death hazard was calculated. Next, individual-level demographic variables were added to the model. Third, area-level variables were added to the model that included all individuallevel variables. Due to similarity between the model that included only the individual-level demographic variables and the fully adjusted model that included both individual-level and area-level variables, we only present the results of the fully adjusted models. Finally, sex and race interactions were tested. Only the sex interaction was significant, so we therefore stratified the analyses.
Since respondents were clustered within census divisions, we conducted clustered survival analysis, using the SAS PROC PHREG procedure with the robust sandwich estimate option. ${ }^{33}$ A category for missing data was created for each variable. Sampling weights were applied to the survey to get representative estimates that may be generalised to the US adult population.

\section{RESULTS}

\section{Demographics}

Fifty-six per cent of the sample was women (table 1). Over $80 \%$ of the sample was white, $15 \%$ were black, with $4.1 \%$ reporting another race. The majority of the sample had a high school diploma as their highest level of education $(52.7 \%)$ with $21.7 \%, 13.7 \%, 6.4 \%$ and $5.4 \%$ reporting not completing high school, a bachelor's degree, graduate degree and junior college, respectively, as their highest education. While only $16.6 \%$ of the sample were categorised as low income (less than $\$ 10000-\$ 14999$ ) and $18.4 \%$ were categorised as medium income ( $\$ 15000-\$ 24$ 999 ), $45.6 \%$ ( $\$ 25000$ or more) were categorised as high income (19.4\% were missing for household income). Sixty-two per cent of the sample were located in urban settings, $25.4 \%$ were in suburban settings and $12.6 \%$ of the sample were in rural settings. Over half the sample was married $(51.8 \%), 13.2 \%$ were divorced, $3.6 \%$ were separated, $10.5 \%$ were widowed and $21.0 \%$ were single. Forty-two per cent of the sample reported an area within a mile of where they lived where they would be afraid to walk alone at night. During follow-up, the cumulative incidence of mortality was $28.1 \% \quad(n=5698)$.

\section{Overall results}

The crude relationship between perceived neighbourhood safety and mortality showed that there was a $14 \%$ increased risk of death (figure 1) among those who responded that they were fearful (HR: 1.14, 95\% CI 1.07 to 1.20 ) at baseline. In the fully adjusted models (table 2 , figure 2), among those who responded that they were fearful in their neighbourhood at night, there was a $6 \%$ increased risk of death during follow-up though this was not significant (HR=1.06, 95\% CI 0.99 to 1.13 ). Overall, women had a reduced risk of death during follow-up (HR=0.68, 95\% CI 0.62 to 0.74) compared with men. Black respondents had an increased risk for death $(\mathrm{HR}=1.32$, 95\% CI 1.19 to 1.47 ) compared with white respondents. There was a reduced risk for death for each education level compared with those with less than a high school diploma though only having a bachelor's or a graduate degree was significant. None of the religious group variables were significantly related with time to death. Those reporting 'high' household income had reduced risk of death (HR=0.81, 95\% CI 0.77 to 0.86) compared with those who reported 'low' household income. Those who were widowed had increased risk for death $(\mathrm{HR}=1.18$, 95\% CI 1.07 to 1.29$)$ compared with those who were married. 
Table 1 Sample demographic characteristics $(n=20297)$

Proportion

n

(\%)

Fear (afraid to walk at night in neighbourhood)

$\begin{array}{lrr}\text { No } & 11758 & 57.9 \\ \text { Yes } & 8539 & 42.1 \\ \text { Sex } & & \\ \text { Male } & 8879 & 43.7 \\ \text { Female } & 11419 & 56.3 \\ \text { Race } & & \\ \text { White } & 16426 & 80.9 \\ \text { Black } & 3044 & 15.0 \\ \text { Other } & 827 & 4.1\end{array}$

Education

Less than high school $\quad 4410 \quad 21.7$

$\begin{array}{lll}\text { High school } \quad 10694 & 52.7\end{array}$

$\begin{array}{lll}\text { Junior college } & 1105 & 5.4\end{array}$

Bachelor degree $\quad 2789 \quad 13.7$

$\begin{array}{lll}\text { Graduate degree } & 1299 & 6.4\end{array}$

$\begin{array}{lrr}\text { Religion } & & \\ \text { Protestant } & 12456 & 61.4 \\ \text { Catholic } & 4904 & 24.2 \\ \text { Jewish } & 381 & 1.9 \\ \text { Other religion } & 639 & 3.1 \\ \text { Eastern } & 51 & 0.3 \\ \text { No religion } & 1866 & 9.2\end{array}$

Age, years

\begin{tabular}{lrr}
$<20$ & 326 & 1.6 \\
\hline $20-30$ & 4046 & 19.9 \\
$31-40$ & 4699 & 23.2 \\
$41-50$ & 3707 & 18.3 \\
$51-60$ & 2680 & 13.2 \\
$61-70$ & 2347 & 11.6 \\
$71-80$ & 1725 & 8.5 \\
$>80$ & 767 & 3.8 \\
Household income & & \\
Low & 3392 & 16.6 \\
Medium & 3753 & 18.4 \\
High & 9298 & 45.5 \\
Missing & 3976 & 19.5 \\
Marital status & & \\
Married & 10506 & 51.8 \\
Divorced & 2674 & 13.2 \\
Separated & 730 & 3.6 \\
Widow & 2128 & 10.5 \\
Single & 4259 & 21.0 \\
Region & & \\
\hline
\end{tabular}

Continued
Table 1 Continued

\begin{tabular}{lrc} 
& \multicolumn{1}{c}{ n } & \multicolumn{1}{c}{$\begin{array}{l}\text { Proportion } \\
\text { (\%) }\end{array}$} \\
\hline New England & 975 & 4.8 \\
\hline Mid-Atlantic & 2929 & 14.4 \\
\hline East North Central & 3695 & 18.2 \\
\hline West North Central & 1631 & 8.0 \\
\hline South Atlantic & 3782 & 18.6 \\
\hline East South Central & 1561 & 7.7 \\
\hline West South Central & 1864 & 9.2 \\
\hline Mountain & 1228 & 6.1 \\
\hline Pacific & 2632 & 13.0 \\
\hline Setting & & \\
\hline Urban & 12587 & 62.0 \\
\hline Suburban & 5149 & 25.4 \\
\hline Rural & 2561 & 12.6 \\
Cohort & & \\
\hline 1980s & 9356 & 46.1 \\
\hline 1990s & 10941 & 53.9 \\
\hline
\end{tabular}

\section{Results stratified by sex}

The crude association (figure 1) between perceived neighbourhood safety and mortality showed that women who were fearful had a $24 \%$ increased risk for death (HR: $1.24,95 \%$ CI 1.16 to 1.32 ) and men who were fearful had a $30 \%$ increased risk for death (HR: 1.30, 95\% CI 1.19 to 1.41). In the fully adjusted models examining risk of mortality stratified by sex (table 3 , figure 2 ), findings were significant among men but not women. Among men, in the adjusted model, there was an $8 \%$ increased risk of death during follow-up among those who experienced fear at baseline in comparison with those who did not experience fear (HR=1.08, 95\% CI 1.02 to 1.14$)$. Black men had a $36 \%$ increased risk of death compared with white men (HR=1.36, 95\% CI 1.17 to 1.59$)$. Men with a bachelor's degree had a $12.7 \%$ reduction in risk of mortality compared with men with less than a high school diploma (HR $=0.87,95 \%$ CI 0.78 to 0.98 ). Males reporting

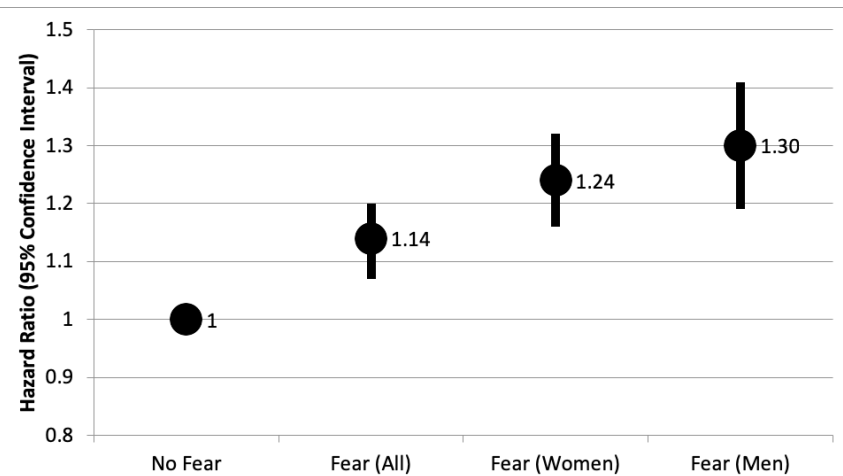

Figure 1 Crude relationship between fear of walking at night in neighbourhood and time to death. 
Table 2 The relationship between neighbourhood fear and time to death among all respondents in the GSS-NDI 1978-2008 $(n=20297)$

\begin{tabular}{lll} 
All respondents $\mathrm{n}=20297$ & \\
\hline Crude & & Adjusted \\
$\mathrm{HR}$ & $95 \% \mathrm{Cl}$
\end{tabular}

Fear

No (reference)

1.00

1.00

Yes

1.14

(1.07 to 1.20 )

1.06

(0.99 to 1.13)

Sex

Male (reference)

Female

0.68

1.00

Race

White (reference)

1.00

Black

1.32

(1.19 to 1.47 )

Other

1.00

(0.82 to 1.23 )

Education

Less than high school

1.00

(reference)

High school

0.89

(0.85 to 0.93 )

Junior college

0.90

(0.80 to 1.02)

Bachelor's degree

0.80

(0.72 to 0.89 )

Graduate

0.87

(0.79 to 0.95 )

Religion

None (reference)

Protestant

1.00

Catholic

1.04

(0.92 to 1.17 )

Jewish

0.95

(0.81 to 1.10$)$

Other

0.85

(0.70 to 1.03$)$

Eastern

0.38

(0.67 to 1.01$)$

(0.08 to 1.79$)$

Age, years

\begin{tabular}{lll} 
18-20 (reference) & & 1.00 \\
$21-30$ & 1.22 & $(0.90$ to 1.67$)$ \\
$31-40$ & 2.03 & $(1.49$ to 2.76$)$ \\
$41-50$ & 3.27 & $(2.26$ to 4.74$)$ \\
$51-60$ & 5.36 & $(3.99$ to 7.19$)$ \\
$61-70$ & 8.75 & $(6.20$ to 12.36$)$ \\
$71-80$ & 13.99 & $(9.87$ to 19.83$)$ \\
$>80$ & 18.94 & $(12.40$ to 28.92) \\
Household income & & 1.00 \\
$\quad$ Low (reference) & & $(0.85$ to 1.00$)$ \\
Medium & 0.93 & $(0.77$ to 0.86$)$ \\
High & 0.81 & $(0.88$ to 1.10$)$ \\
$\quad$ Missing & 0.99 & \\
Marital status & & 1.00 \\
$\quad$ Married (reference) & & $(0.90$ to 1.03$)$ \\
Divorced & 0.96 & $(0.92$ to \\
\hline Separated & 1.06 &
\end{tabular}


Table 2 Continued

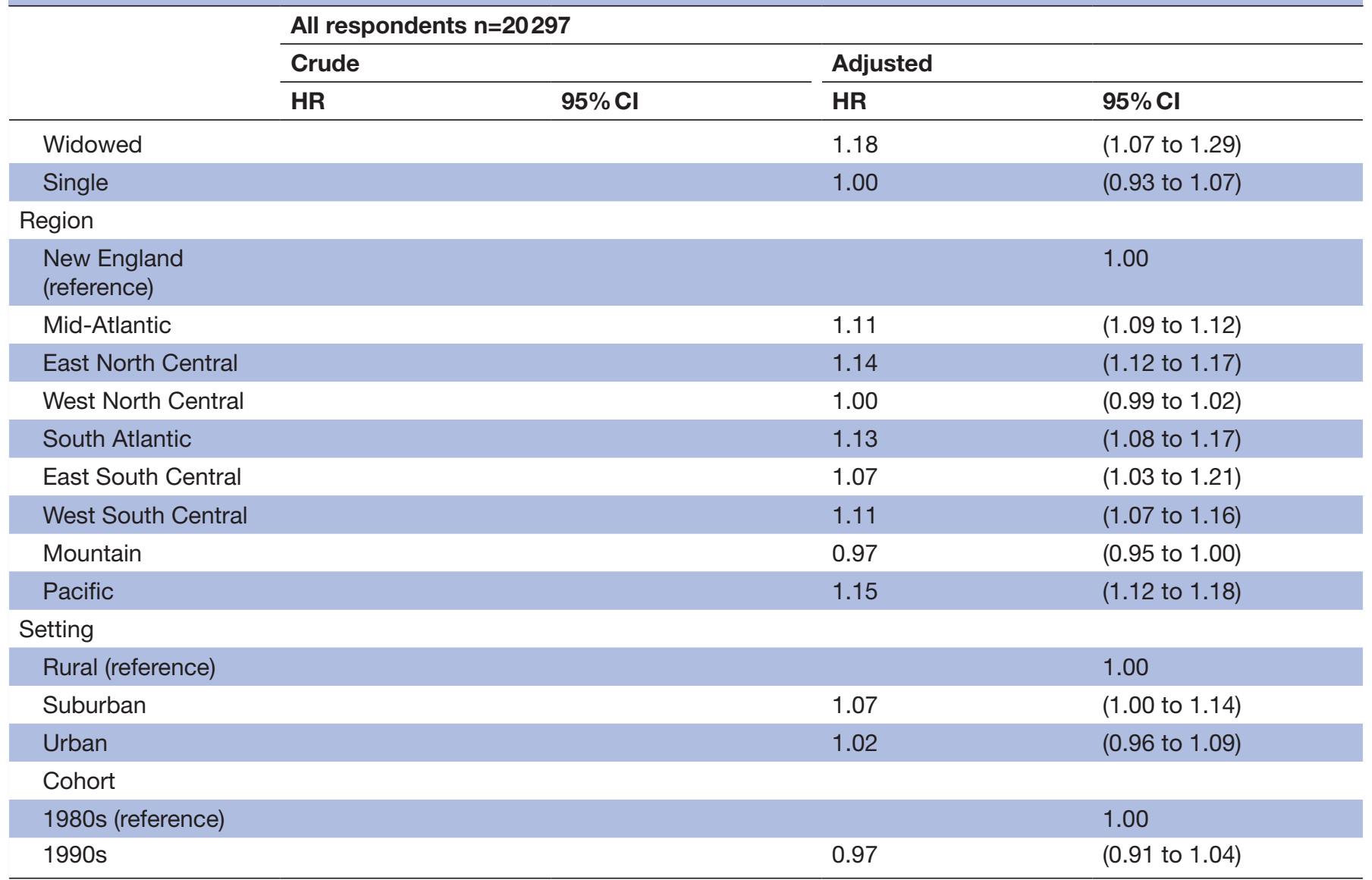

GSS, General Social Survey; NDI, National Death Index.

'high' income had a $22 \%$ reduction in risk of death compared with males reporting 'low' income $(\mathrm{HR}=0.78$, $95 \%$ CI 0.66 to 0.93 ).

Among women, those reporting fear at baseline did not have a significantly increased risk of death compared with women who did not report feeling fearful (HR=1.05, $95 \%$ CI 0.95 to 1.16 ) (figure 2). Black women had a $31 \%$ increased risk of death compared with white women ( $\mathrm{HR}=1.31,95 \%$ CI 1.16 to 1.47$)$. Women who graduated high school $(\mathrm{HR}=0.82,95 \%$ CI 0.74 to 0.91$)$ and women who had a bachelor's degree $(\mathrm{HR}=0.77,95 \% \mathrm{CI}$

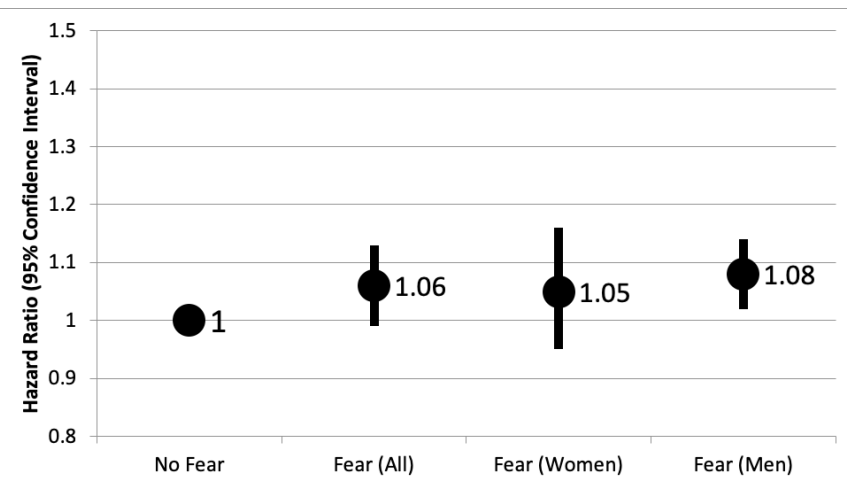

Figure 2 Adjusted relationship between fear of walking at night in neighbourhood and time to death.
0.64 to 0.87 ) had a reduced risk of death compared with women who did not graduate high school. None of the religion variables were significant among women. Women reporting 'medium' income ( $\mathrm{HR}=0.88,95 \%$ CI 0.82 to 0.94 ) and 'high' income ( $\mathrm{HR}=0.84,95 \%$ CI 0.78 to 0.91$)$ had a $12 \%$ and $16 \%$ reduction in risk of death compared with women who report 'low' income.

\section{DISCUSSION}

Although fear of crime may not have predicted time to death among women, there was a significant association between fear and death among men. Fear of walking alone at night in one's neighbourhood was significantly associated with an $8 \%$ increased risk of death for men in the fully adjusted models. To contextualise this result, research shows that veterans with a post-traumatic stress disorder diagnosis had a $5 \%$ increased risk of death compared with the US population as a whole ${ }^{34}$ and conservative and moderate political ideology was associated with a $6 \%$ increased risk of death compared with liberal ideology. ${ }^{32}$ An $8 \%$ change is also meaningful given how prevalent fear of crime is. According to a 2019 Gallup poll, 33\% of respondents reported having an area near their house where they would be afraid to walk at night 
Table 3 The relationship between fear and time to death among respondents in the GSS-NDI 1978-2008 ( $n=20297)$ by sex

\begin{tabular}{|c|c|c|c|c|c|c|c|c|}
\hline & \multicolumn{4}{|c|}{ Females $n=11444$} & \multicolumn{4}{|c|}{ Males $n=8934$} \\
\hline & \multicolumn{2}{|c|}{ Crude } & \multicolumn{2}{|c|}{ Adjusted } & \multicolumn{2}{|c|}{ Crude } & \multicolumn{2}{|c|}{ Adjusted } \\
\hline & HR & $95 \% \mathrm{Cl}$ & HR & $95 \% \mathrm{Cl}$ & HR & $95 \% \mathrm{Cl}$ & HR & $95 \% \mathrm{Cl}$ \\
\hline \multicolumn{9}{|l|}{ Fear } \\
\hline No (reference) & & 1.00 & & 1.00 & & 1.00 & & 1.00 \\
\hline Yes & 1.24 & $\begin{array}{l}(1.16 \text { to } \\
1.32)\end{array}$ & 1.05 & (0.95 to 1.16$)$ & 1.30 & $\begin{array}{l}(1.19 \text { to } \\
1.41)\end{array}$ & 1.08 & (1.02 to 1.14$)$ \\
\hline White & & & & 1.00 & & & & 1.00 \\
\hline Black & & & 1.31 & (1.16 to 1.47 ) & & & 1.36 & (1.17 to 1.59$)$ \\
\hline Other & & & 0.86 & (0.65 to 1.13 ) & & & 1.15 & (0.94 to 1.40$)$ \\
\hline \multicolumn{9}{|l|}{ Education } \\
\hline $\begin{array}{l}\text { Less than high wchool } \\
\text { (reference) }\end{array}$ & & & & 1.00 & & & & 1.00 \\
\hline High school & & & 0.82 & (0.74 to 0.91$)$ & & & 0.96 & (0.86 to 1.07 ) \\
\hline Junior college & & & 0.85 & (0.72 to 1.02$)$ & & & 0.95 & (0.79 to 1.14 ) \\
\hline Bachelor's degree & & & 0.74 & (0.64 to 0.87 ) & & & 0.87 & (0.78 to 0.98$)$ \\
\hline Graduate & & & 0.82 & (0.63 to 1.06$)$ & & & 0.93 & (0.82 to 1.04$)$ \\
\hline \multicolumn{9}{|l|}{ Religion } \\
\hline None (reference) & & & & 1.00 & & & & 1.00 \\
\hline Protestant & & & 0.92 & (0.73 to 1.17 ) & & & 1.10 & (0.88 to 1.37 ) \\
\hline Catholic & & & 0.83 & (0.68 to 1.01 ) & & & 1.02 & (0.80 to 1.29$)$ \\
\hline Jewish & & & 0.78 & (0.59 to 1.04 ) & & & 0.87 & (0.65 to 1.17 ) \\
\hline Other & & & 0.78 & (0.57 to 1.07$)$ & & & 0.84 & (0.66 to 1.07 ) \\
\hline Eastern & & & 1.52 & (0.33 to 7.54$)$ & & & * & * \\
\hline \multicolumn{9}{|l|}{ Age, years } \\
\hline 18-20 (reference) & & & & 1.00 & & & & 1.00 \\
\hline $21-30$ & & & 0.91 & (0.60 to 1.38$)$ & & & 1.59 & (0.88 to 2.88 ) \\
\hline $31-40$ & & & 1.61 & (1.14 to 2.26$)$ & & & 2.50 & (1.33 to 4.72$)$ \\
\hline $41-50$ & & & 2.67 & (1.73 to 4.11$)$ & & & 3.94 & (1.93 to 8.03$)$ \\
\hline $51-60$ & & & 4.34 & (2.99 to 6.29 ) & & & 6.52 & (3.57 to 11.92 ) \\
\hline $61-70$ & & & 6.84 & (4.64 to 10.07 ) & & & 11.19 & (6.15 to 20.37 ) \\
\hline $71-80$ & & & 11.67 & (7.91 to 17.21 ) & & & 16.51 & (8.40 to 32.46$)$ \\
\hline$>80$ & & & 15.89 & $\begin{array}{l}(10.64 \text { to } \\
23.71)\end{array}$ & & & 22.22 & (9.86 to 50.08 ) \\
\hline \multicolumn{9}{|l|}{ Household income } \\
\hline Low (reference) & & & & 1.00 & & & & 1.00 \\
\hline Medium & & & 0.88 & (0.82 to 0.94$)$ & & & 0.96 & (0.81 to 1.14 ) \\
\hline High & & & 0.84 & (0.78 to 0.91$)$ & & & 0.78 & (0.66 to 0.93 ) \\
\hline Missing & & & 1.02 & (0.88 to 1.18$)$ & & & 0.94 & (0.80 to 1.10$)$ \\
\hline \multicolumn{9}{|l|}{ Marital status } \\
\hline Married (reference) & & & & 1.00 & & & & 1.00 \\
\hline Divorced & & & 0.91 & (0.81 to 1.02$)$ & & & 1.03 & (0.95 to 1.12 ) \\
\hline Separated & & & 1.06 & (0.94 to 1.19$)$ & & & 1.06 & (0.76 to 1.49$)$ \\
\hline Widowed & & & 1.21 & (1.11 to 1.33 ) & & & 1.00 & (0.82 to 1.23$)$ \\
\hline Single & & & 1.02 & (0.82 to 1.26$)$ & & & 0.98 & (0.87 to 1.10$)$ \\
\hline \multicolumn{9}{|l|}{ Region } \\
\hline New England (reference) & & & & 1.00 & & & & 1.00 \\
\hline
\end{tabular}


Table 3 Continued

\begin{tabular}{|c|c|c|c|c|c|c|c|c|}
\hline & \multicolumn{4}{|c|}{ Females $n=11444$} & \multicolumn{4}{|c|}{ Males $\mathrm{n}=8934$} \\
\hline & \multicolumn{2}{|c|}{ Crude } & \multicolumn{2}{|c|}{ Adjusted } & \multicolumn{2}{|c|}{ Crude } & \multicolumn{2}{|c|}{ Adjusted } \\
\hline & HR & $95 \% \mathrm{Cl}$ & HR & $95 \% \mathrm{Cl}$ & HR & $95 \% \mathrm{Cl}$ & HR & $95 \% \mathrm{Cl}$ \\
\hline Mid-Atlantic & & & 1.07 & (1.03 to 1.11$)$ & & & 1.14 & (1.12 to 1.16$)$ \\
\hline East North Central & & & 1.13 & (1.10 to 1.17$)$ & & & 1.13 & (1.09 to 1.18$)$ \\
\hline West North Central & & & 0.99 & (0.96 to 1.02 ) & & & 1.01 & (0.97 to 1.05$)$ \\
\hline South Atlantic & & & 1.16 & (1.11 to 1.21$)$ & & & 1.08 & (0.99 to 1.17$)$ \\
\hline East South Central & & & 0.90 & (0.85 to 0.95$)$ & & & 1.30 & (1.20 to 1.40$)$ \\
\hline West South Central & & & 1.02 & (0.99 to 1.07 ) & & & 1.19 & (1.11 to 1.28$)$ \\
\hline Mountain & & & 0.90 & (0.96 to 1.02$)$ & & & 0.96 & (0.91 to 1.01$)$ \\
\hline Pacific & & & 1.19 & (1.12 to 1.26$)$ & & & 1.11 & (1.08 to 1.15$)$ \\
\hline \multicolumn{9}{|l|}{ Setting } \\
\hline Rural (reference) & & & & 1.00 & & & & 1.00 \\
\hline Suburban & & & 1.07 & (1.00 to 1.14$)$ & & & 1.05 & (0.96 to 1.15$)$ \\
\hline Urban & & & 0.98 & (0.89 to 1.09 ) & & & 1.05 & (0.97 to 1.13$)$ \\
\hline \multicolumn{9}{|l|}{ Cohort } \\
\hline 1980s (reference) & & & & 1.00 & & & & 1.00 \\
\hline $1990 s$ & & & 1.03 & (0.96 to 1.12$)$ & & & 0.91 & (0.83 to 1.00$)$ \\
\hline
\end{tabular}

* Estimate unstable due to low power

GSS, General Social Survey; NDI, National Death Index.

and $47 \%$ of respondents reported that they worry about crime and violence a great deal. ${ }^{35}$

Fear of walking alone at night in one's neighbourhood was not significantly associated with mortality risk among women. Although we hypothesised that fear of walking at night in a residential neighbourhood was associated with a greater risk for mortality, we observed significant findings among men only. While women are more likely to report neighbourhood fear, it appears that the effects of the fear are more detrimental among men. Perhaps the different effect seen by gender also is the result of differences in coping styles. The literature has documented differences in coping by gender ${ }^{36}$; however, this relationship seems to be extremely complicated with respect to fear of crime. One paper examined gender differences in the association between general control and safety efficacy with fear of crime and found that safety efficacy, which is associated with reduced fear, was lower among women. ${ }^{37}$ However, this research also shows that safety planning may mitigate the effects of fear and that safety planning is more prevalent among women. The relationship between fear of crime, coping and gender is complex and needs to be examined in future research to better understand these complicated relationships.

While previous literature has examined fear of crime as an exposure for a variety of outcomes in the context of existing effect modification as the result of gender, this literature has mostly found that fear is amplified among women. ${ }^{38}$ However, some research has shown that there is an age/sex interaction showing that fear increases among men with increasing age but not among women (who report higher levels of fear at all ages). ${ }^{39}$ Perhaps this increasing fear among men in older ages as opposed to the more consistently reported levels of fear among women that is what leads to an increased risk of mortality. In addition, fear of crime among men has been shown to be higher when examining crimes for which men are more likely to be victimised. ${ }^{40}$ Thus, while previous effect modification by sex has been shown, the literature is far from uniform with respect to findings and more work should be done to better understand this relationship.

\section{Limitations}

Although the study design was longitudinal, participants were assessed only at baseline. Thus, the potential relationship between time-varying covariates and time to death could not be described. In addition, potentially important variables were not measured including length of time lived in the neighbourhood and whether participants moved between the baseline assessment and death. In addition, lifestyle variables and health related variables were also not included such as exercise habits, diet and tobacco use. Additional contextual covariates such as crime rates, neighbourhood socioeconomic status and walkability were also not included in the analyses due to the fact that it was not possible to link these types of variables to the existing data. Future investigations could involve investigating cross-level interactions between fear and neighbourhoodlevel characteristics such as crime and area-level socioeconomic measures. Another concern is non-differential 
misclassification of the exposure. Since the exposure is only measured once at baseline, it is possible that the exposure status changed over time. Given the fact that nondifferential misclassification always results in an attenuation of observed effects, it is likely that the effect of fear has a larger effect on mortality than observed here. It would be possible to see a significant effect among women with a larger effect size, as well, especially since the trend was in the expected direction. With respect to measurement of fear, another limitation is the use of only one variable to assess fear; however, until 2016, there was only one question asked related to fear of crime. As these data added another question in 2016, subsequent analyses can incorporate both measures once enough time has passed. Another potential limitation in this analysis is reverse causality. Perhaps fear is associated with some additional health outcomes that lead some who are most fearful to an earlier death. However, it is also possible that some health conditions that lead to earlier deaths also cause people with these conditions to be more fearful. One previous study did use IV analysis to try to address potential reverse causality between fear and mental health outcomes and found no support for reverse causality. ${ }^{23}$

\section{Future public health interventions}

Evidence from this investigation indicates that public health interventions might be needed to decrease feelings of fear in an effort to prevent premature mortality. Interventions should include working with communities to create safer neighbourhoods. However, it is well known that fear and risk are not always well correlated. Thus, crime prevention would only result in a partial benefit. Reducing fear of crime should be a priority for communities. Creating community services that help reduce fear, even in the absence of risk, may be beneficial to health and minimise the risk of premature death. Additional community services and the subsequent reductions in fear may encourage more social interaction and outdoor physical activity, thereby leading to health improvements.

A recent systematic review indicated that there is some benefit to reducing fear of crime by improving home security (eg, improved security systems, improved lighting and gating) and by addressing non-crime-related environmental improvements (eg, improvements to recreation facilities, cleaning and repainting transportation facilities). ${ }^{41}$ Thus, public health programming could focus on promoting the security and non-crime-related environmental improvements that have been shown to reduce fear among residents (especially as the non-crime-related environmental improvements would likely result in other positive externalities, as well). Similarly, Crime Prevention Through Environmental Design is the idea that good design and use of the built environment can lead to reductions in crime and also in fear of crime. ${ }^{42}$ A recent study found that the greening of vacant lots was associated with reductions in fear among college students. ${ }^{43}$ Public health programmes can look more into turning vacant lots into green spaces in an effort to reduce fear of crime among residents, which could lead to benefits in improved longevity.

In conclusion, our study, which uses nationally representative data and is therefore generalisable, suggests that fear within the residential neighbourhood is associated with an increased risk for mortality during follow-up among men only. Research has only begun to examine fear as a public health issue. Fear is a potential public health problem that must be examined more fully and better understood.

Contributors EG helped conceive of the idea initially, helped interpret the data and contributed to developing the analytic model. EG drafted the initial paper and revised it substantially with the input of coauthors. She approved the final draft. PM was instrumental in accessing the data as he provides the linkage between the two datasets (General Social Survey - National Death Index (GSS-NDI)). He also helped to analyse the data and provided analytic contributions. He helped revise the paper substantially to improve on the content, and he approved the final draft of the paper. RP helped conceive of the idea initially, contributed to developing the analytic model, performed all statistical analyses and interpreted the data. He helped revise the paper substantially to improve on the content, and he approved the final draft of the paper.

Funding The authors have not declared a specific grant for this research from any funding agency in the public, commercial or not-for-profit sectors.

Competing interests None declared.

Patient consent for publication Not required.

Provenance and peer review Not commissioned; externally peer reviewed.

Data availability statement All datasets for the GSS including the NDI linked files can be accessed publicly: http://gss.norc.org/get-the-data/stata.

Open access This is an open access article distributed in accordance with the Creative Commons Attribution Non Commercial (CC BY-NC 4.0) license, which permits others to distribute, remix, adapt, build upon this work non-commercially, and license their derivative works on different terms, provided the original work is properly cited, appropriate credit is given, any changes made indicated, and the use is non-commercial. See: http://creativecommons.org/licenses/by-nc/4.0/.

\section{ORCID iD}

Erin Grinshteyn http://orcid.org/0000-0003-0883-4248

\section{REFERENCES}

1 Skogan WG, Maxfield MG. Coping with crime: individual and neighborhood reactions. Beverly Hills: Sage Publications, 1981.

2 Garofalo J. The fear of crime: causes and consequences. J Crim Law Criminol 1981;72:839-57.

3 Ross CE, Mirowsky J. Neighborhood disadvantage, disorder, and health. J Health Soc Behav 2001;42:258-76.

4 McEwen BS. Protective and damaging effects of stress mediators. $N$ Engl J Med 1998;338:171-9.

5 Selye $\mathrm{H}$. The physiology and pathology of exposure to stress. Montreal: Acta, Inc, 1950.

6 Cannon WB. Bodily changes in pain, hunger, fear, and RAGE. 2nd edition. Appleton, NY, 1929: 22. 870.

7 Freeman BM. Physiological basis of stress. Proc $R$ Soc Med 1975;68:427-9.

8 Sapolsky RM. Why zebras don't get ulcers. 3rd edition. W.H.Freeman, 2004.

9 Stafford M, Chandola T, Marmot M. Association between fear of crime and mental health and physical functioning. Am J Public Health 2007;97:2076-81.

10 Foster S, Giles-Corti B, Knuiman M. Does fear of crime discourage walkers? A social-ecological exploration of fear as a deterrent to walking. Environ Behav 2012:698-717.

11 Foster S, Knuiman M, Hooper P, et al. Do changes in residents' fear of crime impact their walking? longitudinal results from reside. Prev Med 2014;62:161-6.

12 Fish JS, Ettner S, Ang A, et al. Association of perceived neighborhood safety on body mass index. Am J Public Health 2011:2296-303.

13 Pearson AL, Breetzke GD. The association between the fear of crime, and mental and physical wellbeing in New Zealand. Soc Indic Res 2014;119:281-94. 
14 Macassa G, Winersjo R, Wijk K, et al. Fear of crime and its relationship to self-reported health and stress among men. J Public Health Res 2017.

15 Chandola T. The fear of crime and area differences in health. Health Place 2001;7:105-16.

16 Robinette JW, Charles ST, Gruenewald TL. Vigilance at home: longitudinal analyses of neighborhood safety perceptions and health SSM Popul Health 2016;2:525-30.

17 Sun VK, Stijacic Cenzer I, Kao H, et al. How safe is your neighborhood? perceived neighborhood safety and functional decline in older adults. J Gen Intern Med 2012;27:541-7.

18 Billimek J, Sorkin DH. Self-Reported neighborhood safety and nonadherence to treatment regimens among patients with type 2 diabetes. J Gen Intern Med 2012;27:292-6.

19 Skogan W. Fear of crime and neighborhood change. Crime Justice 1986;8:203-29.

20. Miethe TD. Fear and withdrawal from urban life. Ann Am Acad Pol Soc Sci 1995;539:14-27.

21. Cacioppo JT, Hughes ME, Waite LJ, et al. Loneliness as a specific risk factor for depressive symptoms: cross-sectional and longitudinal analyses. Psychol Aging 2006;21:140-51.

22. Foster S, Hooper P, Knuiman M, et al. Does heightened fear of crime lead to poorer mental health in new suburbs, or vice versa? Soc Sci Med 2016;168:30-4.

23. Grinshteyn EG, Cunningham WE, Eisenman DP, et al. Fear of violent crime and anxiety/depression among adolescents. Mental Health \& Prevention 2017;8:39-45.

24. Ferraro KF. Fear of crime: interpreting victimization risk. Albany, NY: State University of New York Press, 1995.

25. Hale C. Fear of crime: a review of the literature. Int Rev Vict 1996;4:79-150.

26 Snedker KA. Neighborhood conditions and fear of crime a reconsideration of sex differences. Crime Delinquency 2015:45-70.

27 Collins RE. Addressing the inconsistencies in fear of crime research: a meta-analytic review. J Crim Justice 2016;47:21-31.

28 Sutton RM, Gender FS. Gender, socially desirable responding and the fear of crime: are women really more anxious about crime? $\mathrm{Br} J$ Criminol 2004;45:212-24.
29 Kochaneck KD, Murphy SL, Xu J. Mortality in the United States. National Center for Health Statistics, 2017.

30 Davis JA, Smith TW. The NORC General Social Survey: A User's Guide. Newbury Park, CA: Sage Publications, Inc, 1992.

31 Muennig P, Johnson G, Kim J, et al. The general social surveynational death index: an innovative new dataset for the social sciences. BMC Res Notes 2011;4.

32 Pabayo R, Kawachi I, Muennig P. Political Party affiliation, political ideology and mortality. J Epidemiol Community Health 2015;69:423-31.

33. Inc SASI. Sas V. 9.4. Cary, NC, 2015.

34 Forehand JA, Peltzman T, Westgate CL, et al. Causes of excess mortality in veterans treated for posttraumatic stress disorder. Am J Prev Med 2019;57:145-52.

35 Crime. Gallup Poll [Internet], 2019. Available: https://news.gallup. com/poll/1603/crime.aspx [Accessed cited 29 May 2019].

36 Brems C, Johnson ME. Problem-solving appraisal and coping style: the influence of sex-role orientation and gender. J Psychol 1989;123:187-94.

37 Logan T, Walker R. The gender safety gap: examining the impact of victimization history, perceived risk, and personal control. J Interpers Violence 2017;088626051772940.

38 Olofsson N, Lindqvist K, Danielsson I. Fear of crime and psychological and physical abuse associated with ill health in a Swedish population aged 65-84 years. Public Health 2012;126:358-64.

39 Baumer TL. Testing a general model of fear of crime: data from a national sample. J Res Crime Delinq 1985;22:239-55.

40 Reid LW, Konrad M. The gender gap in fear: assessing the interactive effects of gender and perceived risk on fear of crime. Sociological Spectrum 2004;24:399-425.

41 Lorenc T, Petticrew M, Whitehead M, et al. Environmental interventions to reduce fear of crime: systematic review of effectiveness. Syst Rev 2013;2.

42 Jeffery CR. Crime prevention through environmental design. Thousand Oaks, CA: Sage Publications, Inc, 1977.

43 De Biasi A. Transforming vacant lots: investigating an alternative approach to reducing fear of crime. J Environ Psychol 2017:50:125-37. 